\title{
UNIVERSITY OF LEUVEN
}

DEPARTMENT OF PSYCHOLOGY

RESEARCH CENTER FOR

MOTIVATION AND TIME PERSPECTIVE

\section{RESEARCH REPORTS}

Kennon M. SHELDON (University of Missouri, U.S.A.) \&

Maarten VANSTEENKISTE (University of Leuven, Belgium)

PERSONAL GOALS AND TIME-TRAVEL: HOW ARE FUTURE PLACES VISITED, AND IS IT WORTH IT?

Number 130, 2004

Tiensestraat 102

B-3000 Leuven, Belgium

Tel. +32-(0)16-32.60.01

Fax: +32-(0)16-32.59.24

e-mail: psycmp@listserv.cc.kuleuven.ac.be

www.psy.kuleuven.ac.be/motivtim 
Personal goals and time-travel:

How are future places visited, and is it worth it?

\author{
Kennon M. Sheldon \\ University of Missouri, U.S.A. \\ Maarten Vansteenkiste \\ University of Leuven, Belgium
}

KEY WORDS: goals, systemic and organismic perspectives, future time perspective

Note: The contribution of the first author was supported by the Flemish Fund for Scientific Research (FWO-Vlaanderen). 


\section{Time travel, Intentional Activity, (Neg)entropy, and Dissipative Systems}

Time travel. We would like to start with a metaphor. The metaphor is: Personal goals offer a means of traveling through time. By this we do not exactly mean the science fiction plot device, in which time-travel involves "jumping" to the chronological past or future then returning to the chronological present, without "doing the time" in between. Personal goals offer a means of steady forward motion through time, a means of doing the time, such that one arrives at a future place that is to one's liking. By investing and directing one's energy in stable and purposeful ways one may literally create the future, thereby building desirable life-structures of one's choosing. We think that this metaphor can help illustrate two important ideas.

First is the notion that through goal-directed behavior, we can move towards greater personal coherence and complexity over time. In other words, personal goals offer a way to create new life-configurations for ourselves, i.e., elaborated cognitive, familial, social, and vocational networks, that would not have happened otherwise. Because of the obvious importance of this intentional process, much of this chapter will focus on the factors that support personal goal-attainment and thus successful time-travel.

The second idea that the "traveling through time" metaphor conveys is that intentional behavior can make of life a trip -- to future places that we have decided to try to visit, without always knowing what they will be like when we get there. To use a geographical metaphor, committing to a particular personal goal is like starting out on a journey, to a new country or continent that one has never seen. In terms of the time-travel metaphor, it is like selecting a particular future (i.e., a target event or situation in the year 2015) that one will try to visit, hoping that this "place" will be as interesting and positive as one anticipated. However, not every goal-commitment is likely to bring one to the most satisfactory possible future, even if one succeeds in attaining those goals. In other words, not all of the places we might succeed in visiting are nice places, once we get there! Because of the obvious importance of this issue, much of this chapter will focus on the factors that moderate the influence of goalattainment upon positive outcomes such as performance, adaptation, and psychological wellbeing.

(Neg)entropy and intentional activity. A common theme underlying both of these interpretations of time-travel is that of making something happen, while resisting the influences that might deter or detain one from the intended path. In more abstract terms, "traveling through time" involves both creating or approaching negentropy, i.e., organized patterns of functioning or circumstances, as well as avoiding or negating entropy, i.e., the 
disorganization that might be wrought by random or uncontrollable factors. Because of the (neg)entropy concept's potential relevance for understanding human behavior in its temporal context, and also because of its potential for helping psychology achieve greater consilience with the physical sciences (Wilson, 1998), it is worth considering the concept in more detail.

Entropy is the degree of disorder or randomness that exists within a system or environment. Entropy can be conceptualized and measured in many different ways, but the way most relevant for this chapter is to think about it in temporal and probabilistical terms -namely as the tendency for events to occur randomly and haphazardly, so that particular prespecified possible futures (i.e., double sixes, in a dice throw) are unlikely to result just by chance. In contrast, temporal negentropy exists when the sequence of events is highly structured and sequenced, such that a difficult or unlikely future condition is achieved after all.

To illustrate the concept of temporal negentropy in greater detail, consider the following branching corridor metaphor. Suppose that starting from any given present moment, there is a very large (and perhaps infinite) number of possible event chains branching off, leading to the set of "all possible futures." Any particular future or set of futures is only a small subset of the total set of potential futures -- just one particular corridor that reality might or might not take. In stochastic or probabilistic terms, this means that particular possible futures tend to be particularly unlikely, without the intervention of some correspondingly unlikely set of intervening events or circumstances. To use a quantum mechanics analogy, reality is like a wave-function, a manifold buzz of possibilities, awaiting final determination at each successive moment. According to the Copenhagen interpretation of the quantum mechanical equations (Feynman, Leighton, \& Sands, 1995), the particular configuration of particles observed at time $t$ depends, in large part, on when and how the observer makes the observation. The act of making the observation itself serves as the singular or unlikely event that collapses the wave function, elevating one possibility to actuality.

What are the specific events or circumstances that "collapse the wave function" at the level of the individual, affecting life-events such that particular corridors of possible futures are entered, as life proceeds? This is doubtless determined by many factors, including personal history, geographic location, socio-cultural norms, and the like (Sheldon, in press), but herein, we suggest that one important factor determining final life-courses is people's personal goals and intentional activities. In other words, one way to arrive at a particular (preferred) future is to try to intentionally create the new connections, contingencies, and 
coalitions that promise to lead one towards that future. In terms of the branching corridor metaphor, it is not easy to arrive at a particular possible future, because there are so few corridors or event chains that lead in that direction, relative to the set of all possible event chains. Still, if anything can pre-select and then enact particular event chains, human intentional systems can.

Dissipative systems. To further illustrate the nature of self-organizing intentional systems, it is useful to consider the concept of a dissipative system (Glansdorff \& Prigogine, 1971). Dissipative systems were first discovered in the domain of chemical thermodynamics, and have since been demonstrated within the domains of biology, sociology, and culture as well (Jantsch, 1981). They are functional systems consisting of many elements that maintain themselves far from equilibrium (i.e., in an advanced state of order) by neutralizing environmental perturbations to their structure (i.e., they dissipate entropy) through the application of coping mechanisms and compensatory procedures. In other words, dissipative systems develop the means to keep themselves at their current (high) level of order.

However, an important characteristic of dissipative systems is that they can not only counteract entropy, but also reduce it by "jumping" to a new, even more organized mode of functioning (i.e., they achieve negentropy), often in response to unusual threats or stresses. By coping with such challenges, dissipative systems may create new order within themselves, and within their circumstances. As might be obvious, living things are in many ways the sine qua non example of dissipative systems, maintaining themselves far from thermodynamic equilibrium, and at times also further elaborating and developing their structure. This can be seen at many levels of analysis regarding living things, ranging from the level of biological processes (i.e., self-maintaining and self-enhancing cellular systems) to the level of cognitive processes (i.e., self-maintaining and self-enhancing belief systems), and we believe that motivational goal systems also fall into this category.

To summarize, we believe that the dissipative systems idea can capture many characteristics of the active human striver, struggling to stay on course towards particular goals or "possible futures," in the face of influences and setbacks that might dis-entrain her from that course. By attempting to travel (rather than drift) through time, proactive humans may intentionally avoid temporal entropy or disorganization and may achieve greater temporal negentropy or structure, elaborating themselves and their skills in the process.

Having laid out the meta-theoretical foundation of our goal-approach, we can now rephrase our two initial questions before tackling them in more detail. First, what factors enable the active human striver to dissipate entropy and create temporal negentropy? Or, in 
more common language, what factors enable strivers to overcome setbacks and generate creative new approaches to problems, so that they arrive at the intended possible futures? Second, if the human striver manages to attain the self-set possible futures, what factors determine whether the attained possible futures bring about the desired beneficial effects, or whether instead they turn out to be "mistakes", trips the person perhaps should not have taken? In other words, why does not every movement towards negentropy brings along the anticipated satisfaction, and which factors might moderate the relation between movement and satisfaction? In order to answer those two questions, it is helpful to distinguish between two somewhat different conceptualizations of optimal functioning.

\section{Two Conceptions of Optimal Functioning}

Scrutiny of the literature on action, goals, and motivation reveals two major traditions, namely the systemic and organismic perspectives upon optimal functioning (Sheldon \& Kasser, 1995). Much can be learned concerning our questions by considering the difference between them. Systemic perspectives define optimal functioning in terms of the coherent and efficient operation of the person's behavioral or action systems. In other words, these theories focus on the structural coherence of action, such that a larger "quantity" of successful action is achieved. These perspectives include cognitive-behavioral, cybernetic, general systems, and functional theories. In contrast, organismic perspectives define optimal functioning in terms of the satisfaction of psychological needs and the attainment of personal growth and selfactualization. In other words, they focus on the congruence of the action and goal with deeper or more creative and resourceful parts of the self, such that action is of a higher "quality". These perspectives include humanistic, existential, spiritual, and some developmental and psychodynamic theories (Deci \& Ryan, 2000; Sheldon, Williams, \& Joiner, 2003). Below, we will first consider the systemic coherence perspective in detail, in order to demonstrate its importance.

Systemic perspectives. Carver and Scheier's (1981, 1990, 1998) control theory model provides a good framework from which to consider systemic perspectives upon optimal goal functioning. This model depicts human behavior as underlain by a hierarchically ordered system of action units, in which lower-level units exist, ideally, in functional relation to higher-level units. Higher levels are more stable, abstract, and global, whereas lower levels are more transient, concrete, and local. Ideally, higher-level goals set the standards for behavior, which is undertaken in order to reduce discrepancies between present situations and the desired future goals or preferences. Via processes of both negative feedback (using experience as information to adjust behavior to better reduce discrepancies) and positive 
feedback (setting new goals thereby creating new discrepancies to try to reduce), people move forward in time.

Let's consider an example. At a particular moment of time, we find a student driving in his car. What is happening? If we asked him what he is doing, he might say: "I'm going to to the library, to get a book." According to Carver and Scheier, the person's behavior is being controlled by a goal ("get the book"). An elaborated sequence of more specific behaviors is being emitted in order to serve this goal (i.e., the person got in the car, backed out of the driveway, turned left, stopped at the stoplight, etc.). In the process, small discrepancies are steadily eliminated (i.e. the discrepancy between being on Elm street and wanting to be on Oak street), so that the larger discrepancy (between not having the book, and wanting to have the book) can be eliminated.

The above concerns the concrete means by which the goal is reached, i.e. the "how" of retrieving the book. But we also want to know, why is the student retrieving the book? Control theory answers this question by looking further "up" in the action hierarchy. Thus, it may be that the person was getting the book in order to serve the higher-level goal of "getting an A on my paper," which in turn serves the higher-level goal of "earning a high undergraduate GPA," which in turn serves the higher-level goal of "getting into medical school and becoming a doctor." In Carver and Scheier's model all of these levels of behavior can be operating at once, as expressed by every concrete behavior emitted within the sequential stream of behavior.

Notice that from the control theory perspective, the book-retrieving behavior is only intelligible within its broadest context, i.e., when it is understood with relevance to the person's overarching life-goals (i.e., of becoming a doctor). Also, control theory implies that people will be most motivated to engage in a particular action when it is seen as serving the most longer-term or higher-order goals (see Sheldon \& Kasser, 1995, 1998, for supporting data). This assumption locates the theory within a family of theories which posit that the amount of motivation to emit a concrete behavior depends on the perceived instrumentality (Raynor, 1981) or the perceived utility value (Eccles \& Wigfield, 2002) of the behavior for long-term goals. Finally, to return to our meta-theoretical suppositions, notice that successful functioning of the action system can serve to induce much temporal negentropy: it is very unlikely that the student will simply "find himself" in the branch of the future in which he is a doctor, unless he has invested long-term intentional effort into the project.

Starting from this foundation, one can identify a number of potential problems that might occur within an action system, which might prevent a person from making adequate 
forward progress towards desired futures. In terms of the first question raised in the introduction of this chapter, control-theory does an especially good job in illuminating the factors that facilitate versus hinder successful time travel. First, the person may have insufficient skills or abilities relevant to goal-pursuit. For example, a person seeking to go to the library may not be able to drive, and thus may have no way of getting there. In terms of Carver and Scheier's model, necessary lower-level skills or action units may not be in place, so that the discrepancy between current state (no book) and the goal (get book) cannot be reduced. As one illustration of the importance of this factor, Sheldon and Kasser (1998) showed that those with stronger life-skills (such as the abilities to delay gratification, to perceive and follow social norms, and to use emotions as information) better attained their personal goals over a two-month period.

Second, it is also possible to have a relevant skill or ability, but not apply that skill. For example, the non-driver above may have the ability to find and follow a bus schedule, or to call up an acquaintance to ask for a favor, or to ride his bicycle, but he may not think of these action alternatives. In Sheldon and Kasser's (1995) terminology, a person may not have "vertical coherence" in his action system, such that lower and higher level action units fail to contact each other, even though a functional relation is possible. Vertical incoherence may exist not only at lower levels of the action system, such that relatively simple and concrete daily goals are not achieved, but also at higher levels of the action system, such that the person's entire life-plan lacks coherence. For example, a person's daily goals and behaviors might be irrelevant to, or even conflict with, his or her broader ambitions. To return to the aspiring doctor example, the person might spend much of his time trying to beat a particular game on his computer, an activity unlikely to serve any of his longer-term goals.

Third, besides potential inconsistency or conflict between goals at different levels of the action system (vertical incoherence), there can also be inconsistency or conflict between goals at the same level of the action system (Emmons \& King, 1988, termed "horizontal incoherence" by Sheldon and Kasser, 1995). For example, the person driving to the library might also need to complete a calculus assignment that day, finish moving out of his old dorm room, discuss and resolve an issue with his girlfriend, and coordinate a fraternity project, goals which directly conflict with each other because of time and other resource limitations (Wilensky, 1983). He may have to give up one or more of these ambitions.

In sum, systemic perspectives upon optimal goal-functioning can make a number of suggestions and prescriptions for how people may best "travel through time." First, people should develop as many skills as possible that can be used to achieve their self-set goals and 
to attain greater negentropy over time. Second, they should practice recognizing when their skills are relevant to problems-at-hand, so that discrepancies can be reduced whenever possible. Hopefully, concrete skills and short-term goals will directly serve longer-term goals, such that the person can make maximal progress and thus maximally influence which possible futures come to be (vertical coherence). Third, it is good when one's various projects are consistent with each other, so that working on one does not take away from another. Better yet is when one's projects mutually reinforce each other -- as when one can simultaneously pursue the goals of obtaining the library book, visiting a specialty store, and renewing one's driver's license, all in one trip to the other side of town. Here, much is accomplished, via a relatively small overall investment of time and energy (horizontal coherence). See Heckhausen (2002) or Shah and Kruglanski (2000) for other summaries of contemporary systemic approaches, and also for further consideration of the many positive effects of systemic integration upon life-outcomes.

In addition to indicating how goal-attainment can be facilitated, Carver and Scheier's control-theory also has relevance for the second question raised in the introduction of this chapter, namely, whether goal-attainment yields well-being effects. Carver and Scheier assert that people are happier to the extent that they are achieving a larger quantity of goals or, to put it in temporal terms, if they are "moving more quickly" through time. More specifically, people are happiest when their actual goal progress most exceeds their own "meta-goal" regarding the desired rate of progress (Carver \& Scheier, 1990). To illustrate, if the student expects to spend five years studying to become a doctor, but he finishes his studies in four years, he will be happier than if he finishes in the expected five years. From this perspective, the key to happiness is to get as much done as quickly as possible; goal-attainment will lead to well-being, IF it occurs faster than the person expected it to.

Readers may have observed that this analysis suggests that the optimal striver is like an "achievement freak," working constantly to make huge numbers of things happen. In terms of the metaphors developed earlier, such a highly active person travels the furthest distance in time, visiting the most new and/or difficult temporal countries, while also creating the most negentropy in his wake. But is this really the ideal model? What if the person is hyperactive, a slave to his compulsions, who seems to lack all balance in life, or who seems to have cockeyed values and priorities? This is where the organismic perspective comes in.

Organismic perspectives. Again, systemic perspectives on optimal goal-functioning primarily concern efficient and effective functioning by the action system, such that many goals are achieved in short order. However, intuition suggests that other factors matter, also. 
For example, what are the goals that the person is striving for? Are some types or contents of goals (such as for personal growth, emotional intimacy, or community contribution) more healthy or beneficial than other goal types or contents (such as goals for material success, social popularity, or an attractive image)? Also, why, or for what personal reasons, is the person striving for the goals? Does he feel a sense of pressure or a sense of being controlled by external forces, or does he instead feel that the goals are intrinsically interesting, valuable, and important to him? To return to the time-travel metaphor, what is the nature of the future place the person is trying to visit, and, why is the person trying to visit it? Sheldon and Kasser (1995) defined these factors as relevant for two different types of "organismic congruence" (see also Deci \& Ryan, 2000, or Sheldon, Ryan, Kasser, \& Deci, in press). As we hope to show, both the content and the motive factors impact both people's goalattainment (i.e., successful time-travel), and the degree to which goal-attainment produces well-being (i.e., whether the "trip" has been worthwhile). We will first consider the content of goals, below.

The "what" of goals. Considerable research now demonstrates that the particular types of goals a person pursues has implications for her happiness or well-being (Emmons, 1991; Polhman, 2001). For example, Kasser and Ryan (1993) showed that there may be a "dark side" to the American dream, or at least, to one version of the dream -- the ideal of attaining wealth and luxury. Specifically, participants who pursued financial success (an "extrinsic" goal) more strongly than they pursued emotional intimacy, community feeling, and personal growth (three "intrinsic" goals) reported lower well-being, and also showed more evidence of psychopathology during clinical interviews. Notably, in the studies discussed here and below, well-being is most often measured in terms of high positive affect, high lifesatisfaction, and low negative affect.

Kasser and Ryan (1996) extended the extrinsic goal concept, showing that those who strongly value social popularity and physical attractiveness (two more purported extrinsic goals) also evidenced lower well-being. Notably, factor analyses supported the idea that money, beauty, and popularity goals tend to go together, while intimacy, growth, and community goals tend to go together (Kasser \& Ryan, 1996). Thus, Kasser and Ryan's conceptual distinction between the two kinds of goal-content is also echoed in the empirical data.

Sheldon and Kasser (1998) extended these cross-sectional results by conducting a twomonth long study of goal-attainment and its effect on changes in well-being. They showed that attaining goals strongly linked to the three extrinsic "possible futures" listed above had no 
effect upon increasing well-being, whereas attaining goals that were helpfully linked to the three intrinsic futures did have a positive effect upon longitudinal well-being. These findings suggest that some types of vertical coherence may be more beneficial than others -- it depends on what higher-level goals the person's lower-level goals are functionally linked. Again, this issue is typically not represented within purely systemic perspectives upon optimal functioning, which tend to assume that "all goals are created equal" (Ryan, Sheldon, Kasser, \& Deci, 1996).

Notably, the association between strong extrinsic valuing and negative well-being is not large, and thus, people who pursue money, fame and/or beauty harder than they pursue growth, intimacy and community are not necessarily unhappy. Still, it appears that such orientations serve as risk factors for unhappiness, or for less than complete happiness.

What is the source of the content-to-well-being effects? Deci and Ryan $(1985,2000)$ theorize that the over-pursuit of extrinsic goals may fail to meet universal organismic needs, such as the three needs proposed by self-determination theory: for autonomy, competence, and relatedness (Deci \& Ryan, 2000; Ryan \& Deci, 2000; Sheldon, Elliot, Kim, \& Kasser, 2001). For example, a person who is fixated on acquiring wealth or fame may ignore deeper interests and passions, and often feel pressure and tension to perform behaviors he/she does not really want to do (reduced autonomy); also, he/she may often focus on the possibility of negative evaluations by others, or may objectify others, perceiving them as means to selfcentered ends (reduced relatedness); and finally, he/she may feel that wealth or fame outcomes are difficult to attain, and may feel little control over such outcomes (reduced competence; see Kasser, 2002, for a more detailed discussion of these dynamics). According to self-determination theory and considerable empirical data (Sheldon, Ryan, \& Reis, 1996; Sheldon \& Elliot, 1999; Sheldon, Elliot, Kim, \& Kasser, 2001), autonomy, competence, and relatedness are all important for well-being, and the evidence suggests that the process of pursuing extrinsic goals may yield fewer such experiences, on average. This claim was again confirmed in a recent set of empirical studies, showing that employees that value extrinsic work goals over intrinsic work goals display lower positive well-being and more symptoms of burn-out due to a lack of experienced need satisfaction on the work floor (Vansteenkiste, De Witte, Simons, \& Deci, 2003).

The "why" of goals. The second issue relevant to organismic congruence concerns the "why" of goals -- that is, the quality of the reasons for which people pursue goals (Sheldon \& Kasser, 1995). Is the person acting because the actions express his/her developing interests and core values, or is he/she instead acting with a sense of being controlled by external 
constraints or internal compulsions? As we will show below, this question also has considerable relevance for psychological need-satisfaction (Sheldon \& Elliot, 1999; Sheldon, Ryan, Kasser, \& Deci, in press).

To illustrate the many possible kinds of dynamic motives for pursuing a goal, let us return to the "going to get a book at the library" example. The question is, why, personally, does the person in our example want to become a doctor? There are a variety of possibilities: for example, because he sees this goal as a route to external rewards, or as something that his parents expect or demand, as something that will prove his worth and value to others, or as something that will express his personal values and ideals. Or, perhaps, he simply likes learning about medical issues!

The latter reason for acting is not well handled by systemic perspectives, because such perspectives assume that behaviour is always initiated and controlled by some higher-level or more abstract goal. But as in the "pleasure of learning" example above, many behaviors are engaged in simply because they yield enjoyable experiences in the present, not because they are immediately instrumental to some longer-term goal. Self-determination theory calls enjoyment-based reasons for acting "intrinsic motivation," and has demonstrated that intrinsic motivation has strong positive effects on peoples' mood and state of mind, even though they may be largely irrelevant to higher-level goals (Deci \& Ryan, 2000). Notably, intrinsic motivations for acting are conceptualised as distinct from intrinsic types of values, although intrinsic values and intrinsic motivations typically co-vary.

Are all instrumental or extrinsic motivations problematic, to be avoided, according to self-determination theory? No - again, it depends on the type of motivation represented. In addition to focusing on intrinsically-motivated reasons for acting, self-determination theory also distinguishes between three types of extrinsic reasons for acting: external, introjected and identified. These reasons vary in their degree of felt self-determination.

External motivation (striving because external factors seem to "force" one to) is least self-determined, because the person feels no ownership at all of the action. Introjected motivation (striving because one would feel ashamed or guilty if one did not) is slightly more self-determined, since the compulsion is now inside the person, although it is not yet inside the self. Identified motivation (striving because it expresses one's values and ideals, even if the behavior is not enjoyable) is mostly self-determined, since the internal force is now selfcongruent. External, introjected, and identified motivations are all classified as extrinsic motivations, but identified motivation (like intrinsic motivation) is nevertheless viewed as an autonomous or self-determined form of motivation because the person feels a full sense of 
choice and volition in the behavior. In contrast, external and introjected motivations are defined as controlled forms of motivation, because the person feels a sense of compulsion in the behavior.

Although considerable research demonstrates that controlled (external and introjected) forms of motivation tend to have negative effects upon performance and well-being outcomes, whereas autonomous (identified and intrinsic) motives tend to have positive effects (see Sheldon, 2002), this fact is not easily represented within systemic and "quantity"-oriented theories. Whereas organismic perspectives consider the why of motivation in terms of the quality of felt volition for a goal, systemic perspectives address the why question by analyzing the degree of helpful linkage between a goal and the higher-level goals in the person's system. We suggest that these are two equally important, but quite different, ways of considering "why" a person behaves.

The self-concordance concept. Sheldon and colleagues (1999, 2001, 2002) have referred to the feeling that one's goals are caused by the self as "self-concordance" and have operationally defined self-concordance as identified motivation plus intrinsic motivation minus external motivation minus introjected motivation. Thus, self-concordance is, in one sense, just another label for autonomous or self-determined. However, Sheldon (2002) has argued that the concept has an additional or extended meaning in the case of self-generated personal goals and initiatives. Specifically, pursuing one's proactive goals in a selfdetermined manner implies that one has likely chosen the goals based on one's deeper values, interests, needs, and personality preferences rather than upon external forces or non-integrated parts of the self. In other words, self-concordance is thought to measure the "fit" between self and personality, i.e. between peoples' conscious objectives and their underlying dispositions and organismic needs.

From this perspective, the self's ability to correctly intuit the interests, needs and values of its underlying organism, and also the ability to select and act upon goals that are consistent with these, are important skills that are highly relevant to successful "time travel." Self-concordance is a developmental achievement, in which the person has learned to observe his proactive growth and health impulses, and to give them voice. The idea is that people have native gifts and inclinations that they might be advised to try to recognize and develop, rather than blindly following parental, societal, or out-grown self-expectations.

For example: suppose that the student, above, is trying to become a doctor primarily for the money, or because that is what his parents insist upon, or because he hopes that this will finally prove his intelligence, or because he feels strong shame at the thought of failing. 
In other words, he is striving for non-self-concordant reasons. What is the problem with this? First, he may never get there; the data show that, on average, goal-attainment (and thus successful time travel) is less likely to occur when motivation is non-self-concordant (see Sheldon \& Elliot, 1999). Indeed, it seems logical that people would be more resistant to investing sustained effort in goal-pursuits that they feel pressured to pursue or that are not experienced as fitting with their underlying needs and preferences; instead they would tend to give them up, just as people usually give up New Year's resolutions. Second, even if the person manages to reach the goal, he may end up regretting his choice (or, from the existential perspective, regretting his failure to make a more authentic choice; see Sheldon \& Elliot, 1999, and Sheldon \& Kasser, 1998, for supportive data). In terms of the time-travel metaphor, he may arrive at a place in the future from which it is difficult to backtrack, but which, again, is not as satisfying as would be desired. Perhaps he should have pursued some other career besides medicine, such as his recurring idea of attending graduate school in cultural anthropology?

In sum, the organismic perspective on optimal goal-functioning suggests that it is very important to consider not just how effectively or quickly a person is striving, as suggested by control theory and utility theories more generally, but also, towards what a person is striving, and why he/she is striving for it (King, Richards, and Stemmerich, 1998). By considering these questions, we propose that the organismic perspective usefully extends the systemic perspective. Again, however, this does not mean that it supplants it; systemic and organismic perspectives are ultimately complementary, and both are needed to fully understand the nature of optimal human functioning (Sheldon \& Kasser, 1995).

In this summary it is also worth further discussing the fact that control theory and selfdetermination theory think about the "why" of motivation in two different ways, with different implications for optimal functioning. The control theory perspective implies that a person has a good answer to the question "why are you doing that?" if he/she can say "because it is helping me move quickly towards one or more of my broader goals." In terms of the first question of this chapter, he/she might be travelling rapidly through time; however, it is not certain that he/she is moving towards a desirable "place." In contrast, the selfdetermination theory perspective would say that a good answer to the "why" question is "because I enjoy doing the behavior, or because I fully identify with the longer-term goal that the behaviour is serving." In terms of the first question of this chapter, he/she is likely to 
travel more quickly to one's desired place, but he/she is also more likely to experience the place as more satisfying and desirable, once arrived at.

Using Future Time Perspective Theory to Further Compare Systemic and Organismic Approaches

So far, we have tried to clarify how both systemic and organismic theoretical approaches shed light on the time-travel metaphor that we developed in the introduction of this chapter. However, these two perspectives only implicitly deal with the notion of time. Other researchers (Lens, Simons, \& Dewitte, 2002; Stratham, Gleicher, Boninger, \& Edwards, 1994; Zimbardo \& Boyd, 1999) have more directly examined future time perspective, and its impact upon peoples' degree of optimal functioning. It seems important to discuss this research and theory for three reasons. First, goal-striving implies an anticipation of future events, and thus seems to require a future time perspective. In other words, it is likely that future time perspective theory can supply fruitful tools for further analysis of goal-striving processes. Second, future time perspective theory will help us to draw further links between organismic and systemic theoretical perspectives. As we will see, future time perspective theory has traditionally been more like a systemic theory, but has more recently begun introducing organismic concepts into the mix. Third, consideration of future time perspective theory will allow us to discuss a seeming conflict between organismic (present-oriented) and systemic (future-oriented) theories, and to once again show that organismic and systemic perspectives are more complementary than conflicting.

Typically, the concept of future time perspective (FTP) refers to a personality disposition to be preoccupied with the future. Kastenbaum (1961) defined FTP as "a general concern for future events" (p. 204). Wallace (1956) went further and focused on the length or breadth of the temporal vision, defining FTP as "the length of the future time span over which one conceptualises personalised future events" (p. 240). Similarly, Nuttin (1984) defined FTP as the aggregate temporal distance to a person's self-listed goals. The primary question for all of these researchers is: to what extent is the individual not only anticipating the immediate consequences, but also the long-term consequences, of his present behavior (De Volder \& Lens, 1982; Simons, Vansteenkiste \& Lens, in press)? Past research using a variety of FTP measures demonstrated that having a long FTP is correlated with many positive outcomes. These include internal locus of control, the ability to delay gratification, higher grades, taking fewer health and safety risks, and greater psychological well-being (Stratham et al., 1994; 

Zimbardo \& Boyd, 1999; Zimbardo, Keough, \& Boyd, 1997). It appears that a long-term or extended future orientation is a good thing.

Such results seem logical when the concept of FTP is placed in the context of systemic perspectives. Again, systemic perspectives focus on the functional coherence of behaviour, such that discrepancies between current states and desired future states are steadily or speedily reduced. Similarly, FTP theory focuses on the perceived degree of instrumentality of current behaviour for desired future states, so that a person with a long FTP achieves many desirable advantages and adaptations.

However, when considered from an organismic perspective, it seems that being futureoriented might in some cases yield less positive consequences, in the same way that being systemically but not organismically integrated might sometimes create problems. When future oriented, people are almost by definition extrinsically motivated for their present activities, since their actions are, to a large degree, undertaken only as means to some future end. This raises an intriguing question. Are future and instrumental orientations compatible with experiencing immediate pleasure and enjoyment in the moment? That is, can one have both a long FTP and also experience enough satisfaction in the moment to make life worthwhile? This question arises because past research has shown that intrinsic motivation is typically reduced or undermined when people become focused on instrumental rewards that are separable from the task itself (see Deci, Koestner, \& Ryan, 1999, for a comprehensive meta-analysis of this literature). Analogously, we can wonder whether a similar effect occurs for future oriented individuals, so that their enjoyment of the present is necessarily undermined.

Simons, Dewitte, and Lens (2000) recently made an important contribution to resolving this possible conflict between FTP and intrinsic motivation. They showed that when people consider their activities as leading to a future goal that they personally value, their intrinsic motivation for the activity is not undermined. Thus, being oriented towards the future seems quite compatible with experiencing enjoyment in the present, given that the future goal is personally meaningful. These results can be easily interpreted from an SDT perspective. Extrinsically-motivated goals that have been internalized into the self will not undermine intrinsic motivation, because the person has autonomously chosen to engage in them and has thus fully accepted the less-appealing tasks necessary to achieve them (Deci, Patrick, Eghrari, \& Leone, 1994; Deci \& Ryan, 2000). Indeed, identified motivation (the internalised form of extrinsic motivation) and intrinsic motivation are typically positively 
correlated, indicating that these two autonomous forms of motivation are mutually supportive (Sheldon \& Elliot, 1998).

More recent FTP research, also exploring organismic issues, has investigated the possibility that the "what" of goals matters, just as the "why" of goals matters. For example, Vansteenkiste, Simons, Soenens, and Lens (in press) recently demonstrated in an experimental study that when participants were told that their present physical exercise would serve the long-term goal of enhancing their physical attractiveness (an extrinsic goal-content) their enjoyment of the exercises was undermined compared to participants who were not given any future goal for engaging in the exercises. Conversely, when participants' present exercising was linked to the intrinsic future goal of physical fitness, they experienced the exercises as more enjoyable than those who were not given any future goal. Thus, these results indicate that the type or content of future goals contained within the person's FTP helps determine whether they experience their current behavior as enjoyable or not.

In sum, contemporary FTP research is doing precisely what we believe is necessary to extend systemic perspectives upon optimal functioning; namely, consider the specific content of, and the dynamic motives underlying, the "futures" that are sought. Once again, it appears that organismic and systemic perspectives are not necessarily antithetical -- instead, both perspectives are needed to fully understand optimal functioning (Sheldon \& Kasser, 1995).

FTP and present orientation. However, systemic and organismic perspectives might still be viewed as incompatible, from yet another angle. It might be argued that organismic theories, because of their dominant focus on intrinsic motivation and present needsatisfaction, are inherently incompatible with systemic theories, because the latter focus on instrumental motivation and future goal-attainment. In line with this, Strathman and colleagues (1994) suggested that future-orientation and present-orientation form two extremes of a single continuum. In other words, present-oriented individuals cannot also be futureoriented; the two constructs are antithetical to one another. Similarly, organismic congruence (which involves harmonious present experience) and systemic coherence (which involves subordinating present concerns to future concerns) might be incompatible.

We believe this would be an incorrect conclusion, or at least, would be put too strongly. Whether or not present and future orientations are compatible (or not) depends, in large part, on the type of present-orientation involved. At least three different types of present orientation have emerged in recent time-related research: a present-fatalistic orientation, a present-hedonistic orientation (Zimbardo \& Boyd, 1999) and mindfulness (Brown \& Ryan, 
2003). These three concepts all share at least two elements: first, they are said to be quite stable dispositions over time, and second, they are said to reflect a similar time orientation or time focus in which the present is dominating. However, these three present-oriented constructs also differ considerably.

First, a present-fatalistic orientation reflects a negative time attitude and thus yields a rather pessimistic and helpless outlook towards the present and the future. It reveals a belief that 'the future is predestined and can not be uninfluenced by individual actions, whereas the present must be borne with resignation because humans are at the whimsical mercy of fate' (Zimbardo \& Boyd, 1999; p. 1278). Because planning ahead in the future is worthless for such people, the negative correlation of present-fatalistic orientation with future orientation ( $\mathrm{r}$ $=-$.26) reported by Zimbardo and Boyd (1999) does not come as a surprise. A presentfatalistic orientation was also a strong positive predictor of depression and aggression, while it was negatively related to self-esteem.

Second, a present-hedonistic orientation reflects 'a risk-taking, devil may care' attitude towards time (Zimbardo \& Boyd, 1999). Hedonism, which dates back to the philosophical writings of the Greek philosopher Aristippus and utilitarian thinkers as Bentham, equates well-being with experiencing a maximum amount of pleasure, so that happiness consists of the totality of these hedonic moments (Ryan \& Deci, 2001). As a consequence, a present hedonistic orientation is characterised by a focus on immediate pleasure, sensation and excitement, and a readiness to sacrifice today for tomorrow. The expression 'carpe diem' might well define such a present orientation. In line with this definition, Zimbardo and Boyd (1999) found strong positive relations between this type of present orientation and sensation seeking/novelty seeking. Further consistent with Strathman et al.'s single-continuum assumption, Zimbardo and Boyd (1999) also reported that hedonistic present-orientation was negatively correlated with future orientation.

Notably, the label 'hedonistic' suggests that this type of present-orientation should positively predict well-being, and be negatively related to ill-being. In other words, a person who pursues frequent enjoyments and pleasures should be happy, shouldn't she? Surprisingly, however, Zimbardo and Boyd (1999) found hedonism to be positively correlated with depression and aggression, while it was unrelated to self-esteem. Thus, perhaps, being focused only on immediate enjoyment is not so beneficial after all. Why might hedonism be maladaptive? We suggest that hedonistic present-orientations are often adopted in order to cope with or to compensate for a lack of deeper, meaning-based satisfactions in life, and/or to 
compensate for psychological problems that the person wishes to escape. In order to distract themselves from inner conflicting feelings and frustrations, people might start to focus on seeking the next momentary pleasure, thereby continually avoiding the stable, unpleasant aspects of their lives.

In short, both the fatalistic and the hedonistic forms of present-orientation are associated with problems and both seem to be incompatible with being future-oriented. What kind of present-orientation, if any, is positive and beneficial, and might not be antithetical to adopting a future-orientation? We suggest that mindfulness (Brown \& Ryan, 2003) is a valuable candidate. Mindfulness implies a conscious awareness of and a receptive attention to one's inner psychological experiences and states (Brown \& Ryan, 2003; Martin, 1997). Deci and Ryan (1985) argued that such awareness facilitates more self-regulated or autonomous functioning, because it permits introspective access to one's needs, desires and potentials in any given situation, and thereby facilitates the selection of behaviors that are fully congruent with those inner promptings and needs (Brown \& Ryan, 2003). Furthermore, mindfulness does not entail escaping from life-difficulties by hiding in the short-term present, but rather, facilitates the resolution of these difficulties through direct confrontation with the anxieties and frustrations that can accompany them.

When contrasted with a hedonic present-orientation, we suggest that mindfulness reflects an eudaimonic present-orientation. Eudaimonism is an ethical theory rooted in Aristotelian philosophy that calls people to recognise and live in accordance with the 'daimon' or 'true self' (Ryan \& Deci, 2001; Waterman, 1993). The daimon is an ideal in the sense of being an excellent state of self-expression, and any efforts to live in accordance with this perfection give raise to a condition 'eudaimonism.' Mindfulness might well represent one prerequisite for obtaining such a condition, because it allows people to engage in personally expressive activities and to experience higher well-being. The latter supposition was strongly confirmed by Brown and Ryan (2003), who reported that mindfulness predicted well-being of both the hedonic sort (i.e., life satisfaction, positive and negative affect) and eudaimonic sort (i.e., vitality, self-actualization) (Ryan \& Deci, 2001; Vansteenkiste, Lens, Dewitte, DeWitte, \& Deci, in press), and that it was negatively related to ill-being (i.e., depression, anxiety). In sum, there appears to be at least one form of present-orientation which is compatible with a future orientation, although future research will have to establish the positive association of mindfulness with FTP. 
How are mindful present and future orientations compatible, from a functional perspective? Going even further, are there some ways in which a mindful present orientation may actually help a person's future-oriented efforts? We believe that there is. This belief is based on two assumptions: first, that people automatically evaluate the significance of the present moment for their future goals and objectives, and second, that they can access this information, if they are alert to it. Presumably, mindful individuals are alert in this way, that is, they are sensitive to internal information and intuitions bearing upon their future goals and ambitions. In contrast, less mindful people are more likely to lose sight of their future goals, or to fail to notice the relevance of current occurrences for those goals. However, it will take further research to bear out this supposition.

\section{Conclusion}

In this chapter we have developed the metaphor of "traveling through time," not via a magical time machine, but rather, by sustained intentional action. A vision of the active human being was developed, in which people can to some extent create the future through the intentional pursuit of goals. In the process people not only dissipate entropy, they also create new order over time, thereby achieving temporal negentropy. Both systemic and organismic perspectives can make recommendations for effective time-travel, i.e., they can show how people propel themselves through time, rather than merely drifting passively through time. However, while systemic perspectives emphasize the hierarchalized structure of one's goalpursuits and the quantity of one's motivation, organismic perspectives raise the question where such goal hierarchies and quantities come from, and whether the reasons and the content of one's goal-striving are compatible with one's underlying needs, personality, and talents. In other words, the quality of motivation also counts, both as one determinant of motivational "quantity," and as a moderator of goal-attainment's effects upon well-being (Sheldon \& Elliot, 1999).

In the last part of the chapter we used contemporary FTP theory to consider the potential conflicts that might arise between systemic models and organismic models. Again, the potential conflict is that being strongly oriented towards attaining higher-level future goals (systemic coherence) might well cut people off from the present, hindering their ongoing enjoyment and satisfaction in life (organismic congruence); the well-known stereotype of the person who never "stops and smells the roses" comes to mind. However, we tried to show that such a conflict can be avoided if people manage to identify with their non-enjoyable future goals, and/or if they focus on future goals with intrinsic (growth, community, intimacy) 
moreso than extrinsic (money, beauty, popularity) content. As another way of demonstrating the ultimate compatibility of present-oriented and future-oriented personality styles, we discussed mindful present-orientation. We tried to show that, in contrast to fatalistic and hedonistic present-orientation, mindfulness both promotes positive experience in the moment, and, timely movement towards desired possible futures. 


\section{References}

Brown, K. W., \& Ryan, R. M. (2003). The benefits of being present: Mindfulness and its role in psychological well-being. Journal of Personality and Social Psychology, 84, 822848.

Carver, C. S., \& Scheier, M. F. (1981). Attention and self-regulation: A control theory approach to human behavior. New York: Springer-Verlag.

Carver, C. S., \& Scheier, M. F. (1990). Origins and functions of positive and negative affect: A control-process view. Psychological Review, 97, 19-35.

Carver, C. \& Scheier, M. (1998). On the self-regulation of behavior. Cambridge, UK: Cambridge University Press.

De Volder, M., \& Lens, W. (1982). Academic achievement and future time perspective as a cognitive-motivational concept. Journal of Personality and Social Psychology, 42, 566-571.

Deci, E. L., Eghrari, H., Patrick, B. C., \& Leone, D. R. (1994). Facilitating internalization: The self-determination perspective. Journal of Personality, 62, 119-142.

Deci, E. L., Koestner, R., \& Ryan, R. M. (1999). A meta-analytic review of experiments examining the effects of extrinsic rewards on intrinsic motivation. Psychological Bulletin, 25, 627-668.

Deci, E. L., \& Ryan, R. M. (1985). Intrinsic motivation and self-determination in human behavior. New York: Plenum.

Deci, E. L., \& Ryan, R. M. (2000). The "what" and the "why" of goal pursuits: Human needs and the self-determination of behavior. Psychological Inquiry, 11, 227-268.

Eccles, J. S., \& Wigfield, A. (2002). Motivational beliefs, values, and goals. Annual Review of Psychology, 53, 109-132.

Emmons, R. A. (1991). Personal strivings, daily life events, and psychological and physical well-being. Journal of Personality, 59, 453-472.

Emmons, R. A. \& King, L. (1988). Conflict among personal strivings: Immediate and long-term implications for psychological and physical well-being. Journal of Personality and Social Psychology, 54, 1040-1048.

Feynman, R., Leighton, M., \& Sands, M. (1995). Six easy pieces: Essentials of physics, explained by its most brilliant teacher. Reading, MA, US: Addison-Wesley.

Glansdorff, P. \& Prigogine, I. (1971). Thermodynamic theory of structure, stability and fluctuations. New York: Wiley.

Heckhausen, J. (2002). Developmental regulation of life-course transitions: A control theory 
approach. In L. Pulkkinen \& A. Caspi (Eds), Paths to successful development: Personality in the life course. (pp. 257-280). New York, NY, US: Cambridge University Press.

Jantsch, E. (1981). The evolutionary vision: Toward a unifying paradigm of physical, biological, and sociocultural evolution. Boulder, Co: Westview Press.

Kasser, T. (2002). The high price of materialism. London: The MIT Press.

Kasser, T., \& Ryan, R. M. (1993). A dark side of the American dream: Correlates of financial success as a central life aspiration. Journal of Personality and Social Psychology, 65, 410-422.

Kasser, T., \& Ryan, R. M. (1996). Further examining the American dream: differential correlates of intrinsic and extrinsic goals. Personality and Social Psychology Bulletin, 22, 280-287.

Kastenbaum, R. (1961). The dimensions of future time perspective: An experimental analysis. Journal of General Psychology, 65, 203-218.

King, L. A., Richards, J. H., \& Stemmerich, E. (1998). Daily goals, life goals, and worst fears: Means, ends, and subjective well-being. Journal of Personality, 66, 713-744.

Lens, W., Simons, J., \& Dewitte, S. (2002). From Duty To Desire: The Role of Students' Future Time Perspective and Instrumentality Perceptions for Study Motivation and Self-Regulation. In F. Pajares \& T. Urdan (Eds.), Academic motivation of adolescents (pp. 221-245). Greenwich, CT: Information Age Publishing.

Martin, J. R. (1997). Mindfulness: A proposed common factor. Journal of Psychotherapy Integration, 7, 291-312.

Nuttin, J. R. (1984). Motivation, planning and action: A relational theory of behavior. Hillsdale, NJ: Lawrence Erlbaum Associates.

Pohlman, K. (2001). Agency and communion-orientation in life goals: Impacts on goal pursuit strategies and psychological well-being. In P. Schmuck \& K. Sheldon (Eds), Life goals and well-being: Towards a positive psychology of human striving (p. 6884). Gottingen: Hogrefe \& Huber.

Raynor, J. O. (1981). Future orientation and achievement motivation: Toward a theory of personality functioning and change. In G. d'Ydewalle \& W. Lens (Eds.), Cognition in human motivation and learning. (pp. 199-231). Leuven, Belgium \& Hillsdale, NJ: Leuven University Press \& Lawrence Erlbaum Associates, Inc.

Ryan, R. M., \& Deci, E. L. (2001). On happiness and human potentials: A review of research on hedonic and eudaimonic well-being. Annual Review of Psychology, 52, 141-166. 
Ryan, R. M., \& Deci, E. L. (2000). Self-determination theory and the facilitation of intrinsic motivation, social development and well-being. American Psychologist, 55, 68-78.

Ryan, R. M., \& Deci, E. L. (2001). On happiness and human potentials: A review of research on hedonic and eudaimonic well-being. Annual Review of Psychology, 52, 141-166.

Ryan, R. M., Sheldon, K. M., Kasser, T., \& Deci, E. L. (1996). All goals were not created equal: An organismic perspective on the nature of goals and their regulation. In P. M. Gollwitzer \& J. A. Bargh (Eds.), The psychology of action: Linking motivation and cognition to behavior. (pp. 7-26). New York: Guilford.

Shah, James Y; Kruglanski, Arie W. (2000). Aspects of goal networks: Implications for selfregulation. In M. Boekaerts \& P.Pintrichs (Eds); et al. (2000). Handbook of selfregulation. (pp. 85-110). San Diego: Academic Press.

Sheldon, K. M. (2002). The self-concordance model of healthy goal-striving: When personal goals correctly represent the person. In E. L. Deci \& R. M. Ryan (Ed.), Handbook of self-determination research. (pp. 65-86). Rochester, NY: The University of Rochester Press.

Sheldon, K. M. (in press). Optimal human being: Approaching consilience within the person and between the sciences. Erlbaum.

Sheldon, K. M., \& Elliot, A. J. (1998). Not all personal goals are personal: Comparing autonomous and controlled reasons for goals as predictors of effort and attainment. Personality and Social Psychology Bulletin, 5, 546-557.

Sheldon, K. M., \& Elliot, A. J. (1999). Goal-striving, need satisfaction, and well-being: The self-concordance model. Journal of Personality and Social Psychology, 76, 482-497.

Sheldon, K. M., Elliot, A. J., Kim, Y., \& Kasser, T. (2001). What is satisfying about satisfying events? Testing 10 candidate psychological needs. Journal of Personality and Social Psychology, 80, 325-339.

Sheldon, K. M., \& Houser-Marko, L. (2001). Self-concordance, goal-attainment, and the pursuit of happiness: Can their be an upward spiral? Journal of Personality and Social Psychology, 80, 152-165.

Sheldon, K. M., \& Kasser, T. (1995). Coherence and congruence: Two aspects of personality integration. Journal of Personality and Social Psychology, 68, 531-543.

Sheldon, K. M., \& Kasser, T. (1998). Pursuing personal goals: Skills enable progress, but not all progress is beneficial. Personality and Social Psychology Bulletin, 24, 1319-1331.

Sheldon, K. M., \& Kasser T. (2001). Goals, congruence, and positive well-being: new empirical support for humanistic theories. Journal of Humanistic Psychology, 41, 30- 
50.

Sheldon, K. M., Kasser, T., Smith, K., \& Share, T. (2002). Personal goals and psychological growth: Testing an intervention to enhance goal-attainment and personality integration. Journal of Personality, 70, 5-31.

Sheldon, K. M., Ryan, R. M., Kasser, T., \& Deci, E. L. (in press). The independent effects of goal contents and motives on well-being: It's both what you pursue and why you pursue it. Personality and Social Psychology Bulletin.

Sheldon, K.M., Ryan, R.M., \& Reis, H.R. (1996). What makes for a good day? Competence and autonomy in the day and in the person. Personality and Social Psychology Bulletin, 22, 1270-1279.

Sheldon, K. M., Williams, G., \& Joiner, T. (2003). Motivating health: Applying selfdetermination theory in the clinic. Yale: Yale University Press.

Simons, J., Dewitte, S., \& Lens, W. (2000). Wanting to have versus wanting to be: The effect of perceived instrumentality on goal orientation. British Journal of Psychology, 91, 335-351.

Simons, J., Vansteenkiste, M., \& Lens, W. (In press). Placing future time perspective theory in a temporal perspective. Educational Psychology Review.

Stratham, A., Gleicher, F., Boninger, D. S., \& Edwards, C. S. (1994). The consideration of future consequences: Weighting immediate and distant outcomes of behavior. Journal of Personality and Social Psychology, 86, 742-752.

Vansteenkiste, M., Lens, W., Dewitte, S., De Witte, H., \& Deci, E.L. (In press). The 'why' and 'why not' of job search behavior: their relation to searching, unemployment experience and well-being. European Journal of Social Psychology.

Vansteenkiste, M., Simons, J., Soenens, B., \& Lens, W. (in press). How to become a persevering exerciser: The importance of providing a clear, future goal in an autonomy-supportive way. Journal of Sport and Exercise Psychology.

Wallace, M. (1956). Future time perspective in schizophrenia. Journal of Abnormal and Social Psychology, 52, 240-245.

Waterman, A. S. (1993). Two conceptions of happiness: Contrast of personal expressiveness (eudaimonia) and hedonic enjoyment. Journal of Personality and Social Psychology, 64, 678-691.

Wilensky, R. (1983). Planning and understanding: A computational approach to human reasoning. Reading, MA: Addison-Wesley.

Wilson (1998). Consilience: The unity of knowledge. New York: Alfred A. 


\section{Knopf.}

Zimbardo, P. G., \& Boyd, J. N. (1999). Putting time in perspective: A valid, reliable individual-difference metric. Journal of Personality and Social Psychology, 77, 1271 1288.

Zimbardo, P. G., Keough, K. A., \& Boyd, J. N. (1997). Present time perspective as a predictor of risky driving. Personality and Individual Differences, 23, 1007-1023. 